\title{
A TEMPESTADE E A AMÉRICA
}

\section{Bernardo Ricupero}

Teriam os primeiros espectadores de A tempestade associado em 1611 a ilha deserta da peça à América? Embora fosse então relativamente recente o contato entre europeus e americanos, aquela que se considerou, durante muito tempo, a última peça de William Shakespeare foi indiscutivelmente marcada por eventos do Novo Mundo. Em particular, há fortes indícios de que o dramaturgo se inspirou no naufrágio em Bermudas, ocorrido pouco antes, de um navio que trazia para a América, entre outros, o governador da Virgínia. O autor de A tempestade era, além do mais, próximo de investidores da Companhia da Virgínia. Num sentido mais direto, a utopia que o conselheiro do rei de Nápoles, Gonzalo, imagina, ao naufragar na ilha da peça, é diretamente inspirada no ensaio "Dos canibais", de Michel Montaigne. Talvez ainda mais sugestivamente, é possível identificar um dos habitantes da ilha, Caliban, com um índio americano ${ }^{1}$.

1 Em termos textuais, Ariel fala em "to fetch dew from the still-vexed Bermudas" (1. 2. 229). Em tradução livre: "buscar orvalho das Bermudas tempestuosas"; Caliban afirma que a magia de Próspero é suficientemente forte para controlar o deus ve- 
Por outro lado, é afirmado explicitamente em A tempestade que a ilha se localiza em algum lugar entre Nápoles e Túnis. Não por acaso, ressoa o perigo muçulmano numa história transcorrida em lugar de fronteira como o Mediterrâneo, até porque datava de pouco tempo a vitória de cristãos sobre o Império Otomano na batalha de Lepanto (1571). De forma reveladora se objeta o casamento da filha do rei de Nápoles com o filho do rei de Túnis, de onde retornavam os náufragos mais recentes de A tempestade, o irmão do monarca o censurando: "That would not bless our Europe with your daughter, But rather lose her to an African" (2. 1. 119-20 $)^{2}$. Mesmo assim, no contexto renascentista casamentos reais frequentemente funcionavam como importantes instrumentos políticos, como bem sabiam os espectadores da peça de Shakespeare, uma de suas primeiras encenações tendo ocorrido antes do casamento da filha do rei da Inglaterra, Elizabeth, com o eleitor do Palatino, Frederico V. Não 12 menos significativo, a trama conduz para outro casamento, entre Miranda e Ferdinando.

Pode-se mesmo argumentar que há uma ligação fundamental entre o cenário mais imediato de $A$ tempestade, no Mediterrâneo, e seu cenário mais remoto, no Atlântico, já que, como a historiografia vem indicando há algum tempo, existia uma relação triangular entre a Europa, a África e a América, que aproximava os continentes pela navegação, o comércio e a cultura. No que se refere a Shakespeare, pode-se considerar que, depois da sua obsessão inicial com o

nerado por sua mãe, Setebos (1. 2. 373; 5. 1. 261), que era uma deidade dos índios da Patagônia; Trínculo menciona a disposição dos ingleses de pagar "to see a dead Indian" (2. 2. 29), "para ver um índio morto"; e Miranda exclama: "O brave new world That has such people in 't" (5. 1. 183-84), "admirável mundo novo que tem tais habitantes" (Frey, 1976). Essas e todas as demais traduções de trechos de $A$ tempestade presentes neste artigo foram livremente feitas pelo autor, a despeito de terem sido consultadas diversas edições em português.

2 "Não quisestes à nossa Europa conceder a graça de possuir vossa filha, preferindo vir a perdê-la para um africano." 
Mediterrâneo, teria passado a se interessar pelo Atlântico, convertendo-se num bom conhecedor dos relatos dos viajantes sobre o Novo Mundo. Em termos ainda mais próximos, a ilha da peça pode ser identificada com a semiperiferia da Irlanda, uma das primeiras experiências de colonialismo europeu, que serviu como uma espécie de laboratório para as demais. Sugestivamente, quando A tempestade foi encenada pela primeira vez já havia ocorrido a invasão inglesa da ilha vizinha, mas ainda não tinha começado a colonização da mais distante América ${ }^{3}$. Mais especificamente, o contato com o nativo do Novo Mundo já se iniciara, mas ainda não a sua subjugação. Ou ainda, de maneira mais próxima, um personagem como Caliban pode ser visto como um "homem selvagem", ameaça para a civilização presente no seu próprio interior, bastante comum na Europa medieval e renascentista (Brown, 1985; Fielder, 1973; Fuchs, 1997; Greenblatt, 1990; Hulme e Sheerman, 2000; Skura, 1989; Takari, 2009).

Em termos mais amplos, como resume Stephen Orgel: "A tempestade é um texto que parece diferente em diferentes contextos". Assim, Próspero tem sido interpretado "como um governante nobre e mágico, um tirano e megalomaníaco, um nigromante, um cientista neoplatônico, um colonialista imperialista, um civilizador”. De maneira similar, Caliban tem sido visto como "um bruto incapaz de ser educado, um selvagem sensível, um homem selvagem europeu, um nativo do Novo Mundo, horroroso, atraente, trágico, patético, cômico, assustador, o proprietário legítimo da ilha, um escravo natural" (Orgel, 2008, p. 11) ${ }^{4}$. Em resumo, A tempes-

\footnotetext{
3 Era natural para os ingleses fazerem comparações entre os irlandeses e os americanos, o estranho servindo-se, de certa maneira, do familiar. Numa representação já próxima da selvageria, a Irlanda era vista como possuindo uma organização tribal, seu pastoreio como quase nômade e seu cristianismo "papista" como um paganismo mal disfarçado.

4 Patrick Murphy sugere, na mesma linha: "a apropriação de cada época da peça parece desestabilizar preconcepções alternativas sobre o trabalho" (Murphy, 2010, p. 4). Mais especificamente, Alden Vaughan e Virginia Vaughan defendem quanto
} 
tade talvez seja um dos maiores exemplos de como as peças de Shakespeare são trabalhos abertos, que permitem as mais variadas interpretações. Elas talvez revelem mais sobre seus leitores do que sobre os próprios textos. De maneira complementar, a possibilidade dessas leituras alternativas, muitas delas concorrentes entre si, é a maior prova da força da obra do dramaturgo inglês.

\section{Interpretações americanas de $\boldsymbol{A}$ tempestade}

Para meus propósitos neste texto, interessa ressaltar que, apesar dos elementos americanos de A tempestade, só no final do século XVIII a ilha e seus habitantes passaram a ser identificadas pela crítica com o Novo Mundo ${ }^{5}$. Até então, imaginava-se que as alusões americanas da peça eram meramente acidentais. Especial importância para a interpretação americanista de $A$ tempestade teve a vinculação pelo editor dos trabalhos de Shakespeare, Edmond 14 Malone, em 1808, do texto ao relato de William Stachey sobre o naufrágio do Sea Venture e, em termos mais amplos, aos chamados "panfletos das Bermudas". Indo mais longe, o biógrafo do dramaturgo, Sidney Lee, afirmou explicitamente, em 1898, que a ilha da peça seriam as Bermudas; Caliban, um índio americano; e Próspero, um colonizador europeu. Desde então, a leitura americanista de A tempestade se tornou hegemônica (Frey, 1976; Hulme e Sheerman, 2000; Vaughan, 1988; Vaughan e Vaughan, 1999).

\footnotetext{
a Caliban: "cada época tem se apropriado dele e o transformado para corresponder às suas necessidades e pressupostos" (Vaughan e Vaughan, 1999, p. IX). Portanto, o personagem funcionaria como "um significante cultural que muda no tempo e no espaço, na geografia e na cronologia” (Vaughan e Vaughan, 1999, p. XVII).

5 A crítica da peça é especialmente anglo-saxã. Por sua vez, franceses, latino-americanos, caribenhos, africanos e escritores de outras partes do Terceiro Mundo usaram mais livremente $A$ tempestade para pensarem os dilemas de suas sociedades. Esse trabalho lida especialmente com a crítica, outro devendo tratar da especial apropriação da obra de Shakespeare na América Latina.
} 
De fato, não deixa de ser essa uma das possíveis leituras da peça, estimulada especialmente pelas diferentes maneiras com que $A$ tempestade lida com a usurpação. De forma sugestiva, logo no ato 1, cena 2, Próspero conta a Miranda como foram banidos do ducado de Milão por seu irmão Antonio e como depois ocorreu o desterro para a ilha. No entanto, na mesma cena, Caliban conta uma história similar, mas com personagens diferentes: Próspero converte-se no usurpador e o nativo da ilha, em sua vítima ${ }^{6}$.

Em termos históricos, desde o final do século XVIII, houve um deslocamento da centralidade atribuída aos personagens e da própria interpretação de A tempestade. Se inicialmente o papel principal cabia indiscutivelmente a Próspero, sendo valorizada especialmente a sua capacidade de renúncia e conciliação, a partir principalmente do século $\mathrm{XX}$, um personagem que não tem mais de 180 linhas na peça, Caliban, passa a ser estimado devido à sua identificação com o nativo da ilha, a ponto de converter-se, progressivamente, num verdadeiro símbolo do Terceiro Mundo. De maneira paralela, a "interpretação ortodoxa" de A tempestade identificava-a como a última peça de Shakespeare, o que contribuiria para que funcionasse como uma espécie de testamento do dramaturgo. Próspero não controlaria somente a trama da peça, mas toda obra de Shakespeare, confundindo-se, na verdade, o mágico e o dramaturgo ${ }^{7}$. De maneira mais simples, o motivo principal para a identificação de $A$ tempestade com a América e outras experiências coloniais parece ser, como indica Meredith Skura (1989), a evidente

6 Como nota Deborah Willis (1989), ao passo que não se questiona a legitimidade do domínio de Próspero no "centro", o ducado de Milão, a sua posição é mais frágil na "periferia", na ilha.

7 E possível também identificar o mago com Jaime I, ou como uma mescla dele com Shakespeare. Afinal, celebrou-se o casamento da filha do rei numa das primeiras encenações da peça: o monarca buscava a pacificação entre protestantes e católicos e, pouco antes, tinha sido vítima da Conspiração da Pólvora, que tentara derrubá-lo do poder. 
analogia entre as duas tramas. Em resumo, europeus chegam a um novo território, escravizam seus habitantes e se apropriam do que antes pertencia a eles, acreditando, além de tudo, que têm direito a agirem de tal maneira.

Robert Ralston Cowley indicou, já em 1926, o paralelismo da história da relação de Próspero e Caliban com a dos colonizadores europeus e os nativos da América. Sugeriu também que as oscilações na maneira de representar o escravo selvagem e disforme refletiriam oscilações do europeu na sua maneira de entender o americano (apud Vaughan, 1988; Vaughan e Vaughan, 1999). Mais recentemente, Patricia Seed (2000) desenvolveu o argumento, apontando para as bases jurídicas das reivindicações de Próspero e de Caliban à ilha. Em particular, mostra como a trama de A tempestade segue, em linhas gerais, a narrativa inglesa sobre o encontro entre colonizadores e nativos. A relação inicial pacífica - Caliban chega a lembrar: "When 16 thou cam'st first Thou strok'st me and made much of me [...] And then I loved thee And showed thee all the qualities o'th 'isle" (1. 2. 332-36 $)^{8}$ - teria sido seguida por más ações dos nativos que levariam à punição - Próspero se justifica: "Filth as thou art, with humane care, and lodged thee In mine own cell, till thou didst seek to violate The honour of my child" (1. 2. 347-49) ${ }^{9}$. Em compensação, o nativo argumenta, em termos que podem ser tomados como anticoloniais: "This island's mine [...] Which thou tak'st from me" (1. 2. 332) ${ }^{10}$.

Mais precisamente, Caliban defende que seu direito sobre a ilha viria da herança da sua mãe, Sycorax. Já Próspero contra-argumenta que o escravo seria um bastardo, filho da bruxa com o próprio diabo. O mago, por sua vez, baseia

\footnotetext{
8 "Adulavas e considerava-me, quando aqui chegaste [...] naquele tempo, tinha-te amizade, mostrei-te todas as qualidades da ilha".

9 "Sujo como és, tratei-te com humanidade, alojando-te em minha própria cela, até o momento em que ameaçaste violar a honra da minha filha"

10 "Esta ilha é minha [...] Roubaste-me".
} 
sua reivindicação na tentativa de seu antagonista de estuprar sua filha, Miranda. É comum às duas alegações remontarem o suposto direito a mulheres ausentes da discussão. Também não está presente na disputa Ariel, que já morava na ilha quando Sycorax foi exilada de Argel, e pode ser considerado o verdadeiro nativo da ilha. No que concerne ao europeu, está claro que a fonte de seu poder, mais do que a tentativa de violação da filha, é aquilo que cria por meio da sua magia e de sua arte (Hulme e Sheerman, 2000; Orgel, 2008; Skura, 1989).

Para além da relação entre $A$ tempestade e a América, particularmente interessante é perguntar por que ela só passou a ter importância nas interpretações da peça escritas a partir no final do século XVIII. Esse também é o período de emergência do romantismo, podendo-se considerar que a nova sensibilidade que o movimento expressa preparou, de certa maneira, o terreno para leituras "americanistas" de A tempestade. Significativamente, a própria peça de Shakespeare só passou a ser mais encenada no século XIX. Antes, uma adaptação, A tempestade ou a ilha encanta$d a$, escrita, em 1667, por John Dryden e William Davenant, era mais popular do que o trabalho original (Murphy, 2010; Vaughan e Vaughan, 1999).

Desde o romantismo, o ponto de vista de Próspero perde terreno para o de Caliban. Em termos amplos, a interpretação neoclássica de A tempestade argumentava em favor da supremacia da razão sobre as paixões, das virtudes sobre os vícios, da civilidade sobre a selvageria. Defendia-se, portanto, que os impulsos humanos poderiam ser controlados, como faz Próspero ao final da peça. Já românticos, como August Wilhelm Schlegel, Samuel Taylor Coleridge e William Hazlitt, valorizaram a rebeldia de Caliban, vendo-o como um ser poético e nobre e até como o legítimo proprietário da ilha. Por sua vez, a influência do darwinismo fez com que o escravo deformado fosse interpretado 
como uma espécie de elo perdido na cadeia da evolução (Vaughan e Vaughan, 1999) ${ }^{11}$.

Esses exemplos de leituras variadas da peça de Shakespeare indicam que pouco importa a objeção de E. E. Stoll à leitura "americanista": "não há uma palavra em A tempestade sobre a América, ou a Virgínia, colônias ou colonização, índios ou machadinhos, milho, mockingbirds ou tabaco. Nada, a não ser as Bermudas, brevemente referidas como um lugar distante, como Tóquio ou Mandalay" (Stoll apud Frey, 1976, p. 30) ${ }^{12}$. Significativamente, desde a década de 1960, o que Charles Frey (1976), Alden Vaughan e Virginia Vaughan (1988; 1999) chamam de "leituras proféticas" de A tempestade não se preocupam tanto com a relação entre a América e a peça em termos literais, mas com pontos em comuns entre as suas duas histórias, que poderiam até sugerir que a experiência do Novo Mundo corresponderia a uma espécie de encena18 ção do trabalho de Shakespeare. Leo Marx teria iniciado essa interpretação, ressaltando como ponto fundamental de A tempestade a luta do protagonista com a natureza: "a peça é sobre o que acontece a um europeu altamente civilizado quando ele passa a viver na selvageria” (Marx, 1964, p. 41). No fim do trabalho ocorreria, segundo os preceitos do drama pastoral, a reconciliação entre a natureza e a civilização. Já Leslie Fielder, escrevendo no início dos tumultuosos anos 1970, avalia que "toda a história da América imperialista nos foi perfeitamente revelada nesta curta parábola” (Fielder, 1973, p. 238). Não por acaso,

\footnotetext{
11 Nessa referência, Daniel Wilson enxergou, em 1873, Caliban como uma "percepção pré-darwiniana da ligação intermediária entre bruto e homem" (Wilson, 2009, p. 150).

${ }^{12} \mathrm{Na}$ mesma linha, pode-se argumentar que, se a peça é realmente sobre o colonialismo, Próspero seria um estranho colonialista. Não quis viajar para a ilha, não tinha nenhuma intenção de fundar lá um posto avançado de Milão e não tem nenhum interesse em transformar as riquezas da ilha, que Caliban lhe fez conhecer, em mercadoria (Lindley, 2012).
} 
Caliban seria "o primeiro estuprador não branco na literatura dos brancos" (Fielder, 1973, p. 234); sua canção de liberdade "o primeiro poema americano" (Fielder, 1973, p. 236); ao se embriagar, se tornaria "o primeiro índio bêbado da literatura ocidental" (Fielder, 1973, p. 237); comportando-se até como um antecipador da "revolta contra a palavra impressa, a revolta anti-Gutenberg, da qual Marshall McLuhan é atualmente seu principal porta-voz" (Fielder, 1973, pp. 258-59).

Com a crescente influência do pós-estruturalismo na academia anglo-saxã, radicaliza-se a tendência da crítica de não se preocupar com as influências diretas de $A$ tempestade. Mesmo antes, Stephen Greenblatt associou, com grande repercussão, a peça ao que chamou de "colonialismo linguístico”. Entre as visões opostas de que nativos não possuiriam língua e de que não haveria barreira linguística significativa deles com os viajantes vindos do Velho Mundo, Caliban seria colocado "nos limites da diferença para depois se insistir numa misteriosa medida de semelhança" (Greenblatt, 1990, p. 31) dele com Próspero e com os outros europeus. Autores, como Francis Barker, Peter Hulme e Paul Brown, por sua vez, interpretam A tempestade com base principalmente do que chamam de "discurso do colonialismo". Inspiram-se especialmente em Michel Foucault e Edward Said, para argumentar que o contexto discursivo que articularia a peça corresponderia às necessidades da expansão colonial inglesa no seu momento inicial. Ou seja, mais importante do que buscar os textos que Shakespeare leu para escrever sua peça seria entender o discurso no qual operou. A partir dele, seria possível entender quais afirmações poderiam ou não ser feitas pelo dramaturgo e as formas legítimas que elas poderiam assumir. Consequentemente, o foco da análise passaria da suposta intepretação correta da peça para a investigação daquilo a que ela tornaria possível servir. 
É interessante como as "leituras proféticas" e pós-estruturalistas de A tempestade, realizadas no âmbito da academia anglo-saxã, aproximam-se dos usos mais comuns da peça no Terceiro Mundo, onde ela tem servido para se pensar questões que vão além do que poderiam ser as preocupações imediatas de Shakespeare. Provavelmente, a difusão do pós-colonialismo nos dois ambientes serviu até como ponto de contato entre as interpretações. Mas se análises de tal tipo se colocam especialmente contra interpretações a-históricas e formalistas, podem também incorrer em certo anacronismo. Como indica Meredith Skura, é possível, paradoxalmente, que o pós-colonialismo afaste "a peça da situação histórica particular da Inglaterra em 1611 para aproximá-la do que entendemos hoje por colonialismo" (Skura, 1989, p. 47).

Na verdade, boa parte do interesse de A tempestade está em possibilitar pensar os próprios limites da alteridade, 20 mas a partir da situação bastante particular de um inglês no início do século XVII. Bom exemplo do que a peça de Shakespeare pode sugerir aparece no discurso de Gonzalo quando imagina governar uma plantação. Sua posição, a do conselheiro de um príncipe europeu que faz uma crítica radical de suas instituições, é análoga à de Thomas More. Como a visão a respeito dos índios brasileiros de Michel de Montaigne, na qual se baseia a descrição da utopia do conselheiro do rei de Nápoles, o que mais o atrai neles é sua diferença radical em relação aos europeus. Na república de Gonzalo, em que ele "would by contraries Execute all things" (2. 1. 144) ${ }^{13}$, não existiria comércio, direito, educação, agricultura, trabalho, guerra. Em resumo, nessa terra sem mal, "All things in common nature should produce, Without sweat or endeavour" (2.1.156) ${ }^{14}$. Não haveria lugar no Novo

\footnotetext{
13 "Faria tudo pelos seus contrários".

14 "Todas as coisas em comum seriam, sem suor nem esforço, produzidas pela natureza”. Num tom similar, o ensaísta francês do século XVII, ao falar na repú-
} 
Mundo, como apontam ironicamente Sebastião e Antonio, nem mesmo para casamentos, todos, numa situação de amor livre, se comportando como "whores and knaves" (2. 1. $163)^{15}$. Em termos ainda mais fortes, ocorreria, como indicam seus ouvintes, uma contradição nessa república ideal governada por um rei, o que indicaria que "the later end [...] forgets the beginning" (2. 1. 153-54) ${ }^{16}$. Em certa medida, a origem da aporia está no fato de que o questionamento das normas europeias ainda se faz com base em referências europeias (Gillies, 2000; Orgel, 2008).

Mais à frente na peça, o mesmo Gonzalo revela a sua dificuldade de relatar em Nápoles o que encontrara na ilha, considerando que os insulanos "Who though they are of monstrous shape, yet note Their manners are more gentle, kind, than of Our human generation you shall find Many, nay almost any" (3. 3. 31-33) ${ }^{17}$. Ou seja, introduz alguns dos temas mais importantes do debate sobre o Novo Mundo, em que europeus se questionaram sobre a humanidade ou animalidade dos habitantes da América, se eram um exemplo de civilização num estágio inicial ou se tinham uma organização social completamente diferente da sua, isto é, se possuíam algum tipo de ordem social (Lindley, 2012). A questão era,

blica ideal, defende que se os filósofos conhecessem o Novo Mundo não teriam por que pensar em utopias, já que os habitantes da América já viveriam de acordo com seus preceitos: "é uma nação, eu diria a Platão, em que não há nenhuma espécie de comércio, nenhum conhecimento das letras, nenhuma ciência dos números, nenhum termo para magistrado nem para superior político, nenhuma prática de subordinação, de riqueza, ou de pobreza, nem contratos nem sucessões, nem partilhas, nem ocupações além do ócio, nenhum respeito ao parentesco exceto o respeito mútuo, nem vestimentas, nem agricultura, nem metal, nem uso de vinho ou de trigo. As próprias palavras que significam mentira, traição, dissimulação, avareza, inveja, difamação, perdão são desconhecidas. Como ele consideraria distante dessa perfeição a república que imaginou!" (Montaigne, 2010, p. 101)

15 "Putas e vilãos."

16 "O fim esquece o início".

17 "Embora sejam de exterior monstruoso, note, têm modos mais bondosos e gentis do que em boa parte, quase todos, da geração humana que conheço." 
em outras palavras, saber se o nativo era radicalmente um outro ou meramente alguém diferente (Gillies, 2000). Cada uma das posições tem implicações variadas. A visão sobre a alteridade radical pode negar a humanidade dos índios, mas também possibilita um questionamento das normas europeias. Já a posição de que os nativos são menos civilizados reconhece que existe uma base comum deles com os europeus, mas pode justificar a imposição a esses homens bárbaros de uma suposta verdade que ainda não conheceriam (Greenblatt, 1990).

\section{Os habitantes do admirável Mundo Novo}

Outro exemplo das múltiplas possiblidades de leitura de $A$ tempestade é oferecido pela caracterização dos habitantes do admirável Mundo Novo em que ela transcorre: Próspero, Miranda, Caliban e Ariel $^{18}$. O cenário da peça é, por sua vez, sugestivamente descrito apenas como uma ilha deserta ${ }^{19}$.

O legítimo duque de Milão é um mago, cujo maior interesse reside nos livros. Preferiu se recolher à sua biblioteca, deixando que o irmão, Antonio, governasse de fato. Dessa maneira, abriu caminho para a usurpação e o exílio. Chegou à ilha junto com a sua filha, Miranda, devido a um primeiro naufrágio arranjado com a ajuda do seu inimigo, o rei de Nápoles, Alonso.

Próspero se comporta no novo cenário como senhor absoluto. Depende, entretanto, de Caliban e dos outros

\footnotetext{
18 A origem do nome Próspero é latina, vem do verbo prospero, que significa "tornar venturoso, próspero, contente". Miranda, por sua vez, deriva do gerundivo do verbo latino mirar, que quer dizer "aquela que deve ser admirada, maravilhada". A etimologia de Caliban é obscura. A explicação mais popular, desde o século XVIII, sugere que o nome seria um anagrama de "canibal", também referência aos habitantes das ilhas às quais Cristóvão Colombo aportou originalmente, os "caraíbas". Ariel simplesmente indica aéreo (Vaughan e Vaughan, 1999; Lindley, 2012).

${ }^{19}$ John Locke, no final do século XVII, considerou que "a terra que se deixa totalmente à natureza, sem qualquer melhoramento de pastagem, lavra ou plantação, se chama, como em verdade o é, 'deserto" (Locke, 1973, p. 57). No mesmo livro também considerou que, "no início, toda terra era América" (Locke 1973, p. 60).
} 
habitantes da ilha para exercer sua autoridade, como lhe lembra seu escravo: "For I am all the subjects that you have" (1. 2. 341 $)^{20}$. Isto é, indica-se que a dominação sempre é sobre alguém. A fonte de poder do duque deposto, como também bem percebe Caliban, é sua biblioteca, sem a qual, "He's but a sot, as I am" (3. 2. 85) 21. Portanto, para vencê-lo, bastaria "Burn but his books" (3. 2. 87) ${ }^{22}$.

Fazendo uso de sua biblioteca, Próspero pratica magia. O status dessa magia é, porém, ambivalente, como era comum no Renascimento. Tem algo de ciência, nos moldes de Francis Bacon, que, amparada na filosofia neoplatônica, estuda empiricamente a natureza, e ao mesmo tempo também de alquimia, ou de simples ilusionismo. Significativamente, a história do mago apresenta diversos paralelos com a da antiga senhora da ilha, Sycorax. Como a bruxa, foi banido de sua terra natal; a ilha lhe deu uma nova vida, corporificada nos filhos Caliban e Miranda; Ariel serviu a ambos como escravo; os dois controlam os numerosos espíritos naturais presentes no novo ambiente. A magia de Próspero funciona, entretanto, principalmente como fonte de poder sobre outros homens. Mais importante, ao final da peça, o duque renuncia a ela e, ligado a isso, ao possível desejo de vingança. Pode-se especular que, a partir daí, também o caminho se abre mais facilmente para um mundo novo e desencantado.

A única personagem feminina da peça, Miranda, é descrita apenas como "filha de Próspero". Talvez relacionada a essa caracterização, foi encarada, durante muito tempo, com pouca simpatia pelas feministas. A filha de Próspero era vista como um ser passivo, disposto a se submeter às maquinações do duque com outros homens, com vistas a preparar seu casamento com o filho do rei de Nápoles. Também a

\footnotetext{
20 "Eu sou todos os vassalos de que dispondes."

21 "É um palerma como eu."

22 "Queimar-lhe os livros."
} 
sua sexualidade sofreria o controle masculino de Próspero, especialmente temeroso de que Miranda e Ferdinando consumassem o ato sexual antes do casamento. Nessa linha, Ann Thompson enxerga em A tempestade uma "obsessão com temas de fertilidade e castidade" (Thompson, 2009, p. 401). Por outro lado, tal obsessão poderia indicar um desejo incestuoso do pai pelo corpo da filha. A nova ortodoxia pós-colonial não tem, por sua vez, grande interesse pela quase menina, voltando a sua atenção especialmente para o contraste entre Próspero e Caliban.

Em compensação, é possível, na esteira de Jessica Slights (2001), destacar um aspecto menos evidente. A adolescente não deixa de ser uma agente moral, agindo de maneira pouco comum no século XVII, ao tomar a iniciativa na relação com o futuro marido: "I am your wife, if you will marry me" (3. 1. 85) ${ }^{23}$. Pouco depois, insiste em como o casal seria indissociável, mesmo que o amado não a dese24 jasse. Mas, para que isso ocorresse, promete, curiosamente, servidão: "You may deny me, but I'll be your servant Wheter you will or no" (3. 1. 86-87) ${ }^{24}$.

Caliban é descrito como um "selvagem e deformado escravo”. A caracterização aponta para uma condição e dois atributos: ser um escravo, com comportamento selvagem e aparência deformada. Qualidades e condição estão relacionadas, já que são a selvageria e a deformidade que justificam a escravidão do filho de Sycorax.

O escravo é decisivo para a existência de Próspero e Miranda na ilha, até porque, como aponta o duque para a sua filha: "He does make our fire, Fetch in our wood, and serves in offices That profit us" (1.2.312) ${ }^{25}$. Isto é, Caliban, como outros submetidos ao colonialismo, realiza toda a

\footnotetext{
23 "Sou vossa esposa, se me desposardes."

${ }_{24}$ "Podeis me recusar por companheira, mas vossa serva poderei ser sempre, quer o queiras, quer não."

25 "É quem nos faz fogo, nos traz lenha e nos presta serviços de utilidade".
} 
gama de trabalhos que seus mestres acham necessários e lhes impõem.

Por sua vez, a descrição do nativo da ilha como deformado indica que sua situação era, de fato, comparável à do indígena americano, de cuja humanidade os europeus chegaram a duvidar ${ }^{26}$. Quando Trínculo encontra-o, pela primeira vez, pergunta: "What have we here - a man, or a fish?" (2. 2. 23) ${ }^{27}$. Inclina-se inicialmente pela segunda opção, já que "A fish, he smells like a fish" (2. 2. 24) ${ }^{28}$. No entanto, acaba concluindo que aquele que tem pernas de gente é "An islander, than hath lately suffered by a thunderbolt" (2. 2. $32)^{29}$. Mais importante, entre uma consideração e outra, avalia que se estivesse na Inglaterra "had but this fish painted, not a Holiday-fool there would give a piece of silver" $(2.2 .25)^{30}$, sempre existindo quem tenha disposição de desembolsar algum dinheiro "to see a dead Indian" (2. 2. 29) ${ }^{31}$. Em poucas palavras, independentemente da humanidade ou não de Caliban, ele é enxergado como uma possível fonte de ganho. O palhaço percebe, dessa maneira, que o ser deformado poderia mudar sua sorte: "There would this monster make a man" (2. 2. 26) ${ }^{32}$.

A selvageria de Caliban é central na peça, até porque é em contraste com ela que se revela a civilidade dos outros personagens. Próspero associa essa característica de seu escravo a não saber falar. Miranda não teria poupado esfor-

\footnotetext{
${ }^{26}$ Leslie Fiedler resume a questão: "dizer que Caliban era um índio para Shakespeare equivale a dizer que ele era um problema já que sua época histórica não tinha sido capaz de decidir o que, de fato, eram os índios" (Fielder, 1973, p. 233).

27 "Que temos aqui - é homem ou peixe?" Wilson (2009) relaciona, em termos darwinistas, o aspecto de peixe de Caliban à origem aquática do homem. Trínculo e Stefano normalmente o chamam de monstro, algumas vezes ajuntando "monstro ridículo", "monstro bêbado", "monstro-servo", "monstro-homem", "monsieur-monstro", "monstro ignorante" etc.

28 "Um peixe, ele cheira como peixe."

29 "Um ilhéu que a trovoada derrubou."

30 "Não haveria tolo de feira que não pagasse uma moeda de prata para vê-lo."

31 "Para ver um índio morto."

32 "Este monstro faria um homem."
} 
ços para ensiná-lo sua língua ${ }^{33}$. Numa das linhas mais fortes e famosas da peça, o escravo admite ter aprendido com seu mestre e sua filha, mas os maldiz por isso: "You taught me language, and my profit on't Is, I know how to curse. The red plague rid you for learning me your language!" (1. 2. 363-64) ${ }^{34}$.

Aqui, particularmente, a analogia de Caliban com o índio do Novo Mundo é marcante. Como assinala Greenblatt (1990), a ideia de que os nativos da América não possuíam língua já aparece no diário de Colombo, em que revela a intenção de levar índios para a Europa que poderiam aprender a falar. Nesse sentido, o indígena é visto como alguém literal e culturalmente pelado, sua situação equivalendo a uma espécie de tabula rasa, a ser preenchida pela civilização europeia. Do ponto de vista do nativo, a noção de que só pode falar por meio da língua do colonizador indica até que ponto chega a sua opressão (Lindley, 2012).

Caliban se mostra pronto a se rebelar contra Próspero, 26 associando-se, para tanto, a Trínculo e Stefano. No entanto, a conspiração do selvagem com o "palhaço" e o "mordomo bêbado" tem um certo ar de delírio embriagado, sugerindo-se que uma aliança do escravo com os náufragos plebeus produz, no máximo, uma revolução cômica. No entanto, mais uma vez de maneira sugestiva se pensarmos na história posterior da América, os rebeldes acabam sendo perseguidos por espíritos que assumem a forma de cães. No que se refere a Caliban, passar a ter um novo mestre parece ser mais importante do que ganhar a liberdade: "Ban, ban, $\mathrm{Ca}$ -caliban Has a new master - get a new man. Freedom, high-day, high-day freedom, freedom high-day, freedom" (2. 2. 160-62) ${ }^{35}$.

\footnotetext{
${ }^{33}$ Em algumas versões da peça, a fala em que se revela os esforços de educação de Caliban é atribuída a Próspero e não a Miranda.

34 "A falar me ensinastes, em verdade. Minha vantagem nisso é ter ficado sabendo como amaldiçoar. Que a peste vermelha vos carregue, por me terdes ensinado a falar vossa língua."

35 "Ban, ban, ban, Caliban. Tem mestre novo amanhã. Liberdade, viva! Viva a liberdade! Liberdade!"
} 
Dessa maneira se confirmaria, paradoxalmente, que, se o selvagem é capaz de revolta, não pode ser livre, parecendo equivaler, em termos aristotélicos, a um escravo natural.

A relação de Próspero com Ariel é muito diferente daquela que tem com Caliban. O duque nutre certa consideração pelo espírito do ar e mesmo carinho. Tais sentimentos ficam claros nas vezes em que se dirige a ele, chamando-o de "meu bravo espírito"; "meu precioso Ariel"; "meu delicado Ariel"; "querido Ariel"; "meu servo diligente"; "meu gentil Ariel"; "meu Ariel". Entende-se tal afinidade pelas próprias características do espírito, associadas à leveza e à afabilidade. Ariel, em compensação, pode ser interpretado como a fantasia do colonizador sobre o nativo que aceita seu domínio (Fuchs, 1997).

Por sua vez, há diversos pontos semelhantes entre Caliban e Miranda. Ambos cresceram na ilha, sendo educados e submetidos à autoridade de Próspero. Não por acaso, também a virgem, na sua inocência não corrompida pela Corte, pode ser identificada com a América. Contudo, os resultados do experimento de ensino nos dois são opostos: a figura feminina é um exemplo de graça civilizada, ao passo que a masculina é selvagem e deformada. De acordo com Brown (1985), é decisivo no contraste entre os dois o discurso da sexualidade: a tentativa de violação de Miranda por Caliban justificando a sua subjugação, enquanto que a sexualidade da filha de Próspero é controlada por meio do casamento. Seria especialmente característica da selvageria do escravo a sua incapacidade de controlar as paixões. Não por acaso, não refuta a acusação de ter tentado estuprar Miranda, apenas lamenta: "O ho, O ho! Would't had been done. Thou didst prevent me - I had peopled else this isle with Calibans" (1. 2. 350-51) ${ }^{36}$.

36 "Oh oh! Oh oh! Quisera tê-lo feito; mas me impediste. Se não fora isso, com Calibans houvera a ilha povoado." 
A oposição entre Caliban e Ariel é ainda maior, um sendo praticamente definido em confronto com o outro. Se o primeiro é terra (1. 2. 314), sendo marcado pela paixão e a brutalidade, o segundo é ar (5. 1. 21), ser assexuado e delicado. O contraste entre o ser selvagem e o espírito alado foi especialmente importante para neoclássicos, que a entenderam em termos da oposição entre corpo e mente. Mas, desde então, Ariel tem perdido espaço para Caliban. Os dois têm em comum, porém, o fato de serem escravos de Próspero. A diferença é que a servidão do selvagem parece ser interminável, acreditando-se, em contraste, que a do espírito, algum dia, chegará ao fim. Mesmo assim, ambos anseiam por liberdade.

Tem sido comum interpretar Caliban como o escravo rebelde, enquanto Ariel seria o escravo submisso, grato a Próspero por lhe ter libertado da árvore na qual Sycorax o havia aprisionado. No entanto, a gratidão do espírito do ar 28 nunca é completa, até porque deixa de ser servo da bruxa apenas para passar a ter um novo senhor. Assim, o duque só mantém o domínio sobre esse escravo por meio de promessas, ameaças e a insistência na necessidade de ser grato. Na verdade, é possível, como defende David Lindley, interpretar Ariel e Caliban "como figuras complementares que funcionam menos como indivíduos do que como representações de aspectos do próprio Próspero" (Lindley, 2012, p. 64).

Normalmente se associa Próspero especialmente a Caliban, no bárbaro se encontrando características também presentes no mago, mas que ele recusa, como a raiva, a paixão, o desejo de vingança e a sexualidade (Brown, 1985; Orgel, 2008). De maneira reveladora, o duque reconhece, no final da peça, a sua identificação com o escravo: "this thing of darkness, I Acknowledge mine" (5. 1. 274) ${ }^{37}$. Contudo, pode-se

37 "Esta coisa escura que sei que é minha." 
também dizer que é o espírito do ar que realiza os propósitos do mago, quando cria a tempestade que inicia a peça, encanta outros personagens para que durmam, toma a aparência de uma harpa, torna-se invisível e controla espíritos menores. Mais importante, é Ariel que convence Próspero da necessidade do perdão e da reconciliação ${ }^{38}$.

No entanto, o espírito delicado é atualmente entendido mais como um escravo submisso. Na verdade, um dos pontos mais interessantes de A tempestade é como, em quatrocentos anos, Próspero se converteu de um senhor sábio num opressor colonial, Miranda de uma virgem pura se tornou uma vítima do patriarcalismo, Caliban de um monstro selvagem passou a ser um símbolo do Terceiro Mundo. Ao longo desse período, a América, independente da vontade de Shakespeare, se transformou, de fato, na ilha da peça. É verdade que essas representações dos habitantes e da ilha de A tempestade são reveladoras especialmente de sensibilidades cambiantes. Mesmo assim, essas possibilidades de interpretação já estavam presentes na peça. A tempestade funciona, dessa maneira, como uma rica fonte de símbolos e metáforas para se pensar a América e não apenas a América.

\section{Bernardo Ricupero}

é professor do Departamento de Ciência Política da Universidade de São Paulo (USP), pesquisador do Centro de Estudos de Cultura Contemporânea (Cedec) e pesquisador do Conselho Nacional de Desenvolvimento Científico e Tecnológico $(\mathrm{CNPq})$.

\footnotetext{
${ }^{38}$ A reconciliação não é, entretanto, completa, já que dela não participa o irmão usurpador, Antonio.
} 


\section{Bibliografia}

BARKER, F.; HULME, P. 2009. "Nymphs and Reapers heavily vanish: the discursive con-texts of The tempest”. In: GRAFF, G.; PHELAN, J. A case study in critical controversy: The tempest. Boston: Bedford/St. Martin's.

BROWN, P. 1985. "This thing of darkness I acknowledge mine: The tempest and the discourse of colonialism”. In: DOLLIMORE, J.; SINFIELD, A. Political Shakespeare: new essays in cultural materialism. Ithaca: Cornell University Press.

FIELDER, L. 1973. The stranger in Shakespeare. London: Croom Helm. FREY, C. 1976. "The tempest and the New World”. Shakespeare Quartely, v. 30, n. 1.

FUCHS, B. 1997. "Conquering islands: contextualizing The tempest". Shakespeare Quartely, v. 48, n. 1.

GILLIES, J. 2000. "The figure of the New World in The tempest". In: HULME, P.; SHEERMAN, W. (orgs.). The tempest and its travels. London: Reakton Books.

GRAFF, G.; PHELAN, J. 2009. A case study in critical controversy: The tempest. Boston: Bedford/St. Martin's.

GREENBLATT, S. 1990. Learning to curse. New York: Routledge.

HULME, P.; SHEERMAN, W. 2000. "Introduction". In: HULME, P.;

SHEERMAN, W. (orgs.). The tempest and its travels. London: Reakton Books.

LINDLEY, D. 2012. “Introduction”. In: SHAKESPEARE, W. The tempest.

Cambridge: Cambridge University Press.

LOCKE, J. 1973. Segundo tratado sobre o governo. Trad. E. Jacy Monteiro.

Coleção Os Pensadores, v. XVIIII. São Paulo: Abril Cultural.

MARX, L. 1964. "Shakespeare's American fable". The Massachusetts Review, v. 2 , n. 1 .

MONTAIGNE, M. 2010. Os ensaios. Trad. Rosa Freire D’Aguiar. São Paulo: Penguin.

MURPHY, P. M. 2010. "Interpreting The tempest. A history of its readings".

In: MURPHY, P. M. The tempest: critical essays. New York: Routledge.

ORGEL, S. 2008. "Introduction". In: SHAKESPEARE, W. The tempest.

Oxford: Oxford University Press.

SEED, P. 2000. "This island's mine: Caliban's native sovereignty". In:

HULME, P.; SHEERMAN, W. (orgs.). The tempest and its travels. London:

Reakton Books.

SHAKESPEARE, W. 2008. The tempest. Oxford: Oxford University

Press.

2012. The tempest. Cambridge: Cambridge University Press. 
2005. A tempestade. Trad. Carlos Alberto Nunes. São Paulo: Martin Claret. . 2011. A tempestade. Trad. Barbara Heliodora. Rio de Janeiro: Nova Fronteira.

SLIGHTS, J. 2001. "Rape and the romanticization of Shakespeare's Miranda”. Studies in English Literature, v. 41, n. 2.

SKURA, M. A. 1989. "Discourse and the individual: the case of colonialism in the Tempest". Shakespeare Quartely, v. 40, n. 1.

TAKARI, R. 2009. "The tempest in the wilderness”. In: GRAFF, G.; PHELAN, J. A case study in critical controversy: The tempest. Boston: Bedford/St. Martin's.

THOMPSON, A. 2009. "Miranda, where's your sister? Reading Shakespeare's The tempest”. In: GRAFF, G.; PHELAN, J. A case study in critical controversy: The tempest. Boston: Bedford/St. Martin's.

VAUGHAN, A. T. 1988. "The americanization of Caliban". Shakespeare Quartely, v. 39, n. 2.

VAUGHAN A. T.; VAUGHAN, V. M. 1999. Shakespeare's Caliban: a cultural history. Cambridge: Cambridge University Press.

WILSON, D. 2009. “The monster 'Caliban'”. In: GRAFF, G.; PHELAN, J. A case study in critical controversy: The tempest. Boston: Bedford/St. Martin's.

WILLIS, D. 1989. "Shakespeare's The tempest and the discourse of colonialism”. Studies in English Literature, v. 29, n. 2. 


\section{A TEMPESTADE E A AMÉRICA}

\section{BERNARDO RICUPERO}

Resumo: O artigo examina como a crítica entendeu, ao longo do tempo, a relação entre $A$ tempestade e a América. Destaca as atitudes cambiantes sobre a peça de William Shakespeare e os habitantes da ilha onde ela se desenrola. Mostra, em especial, como Próspero, de um governante sábio, converte-se num tirano colonialista, ao passo que Caliban, de monstro selvagem, torna-se um símbolo do Terceiro Mundo. Nesse sentido, A tempestade é interpretada como uma rica fonte de metáforas para se pensar a América.

Palavras-chave: A tempestade; América; Shakespeare; Próspero; Caliban; Pós-colonialismo.

\section{THE TEMIPEST AND AMERICA}

Abstract: The article examines how the relationship between The tempest and America was understood throughout history. It emphasizes the changing attitudes towards William Shakespeare's play and the inhabitants of the island where it takes place. It points out, specially, how Prospero, from a wise ruler becomes a colonialist tyrant, while Caliban, from a savage monster is transformed into a Third World symbol. Thus, The tempest is seen as a rich source of metaphors to think America.

Keywords: The tempest; America; Shakespeare; Prospero; Caliban; Post-Colonialism. 